\title{
FIBROSIS OF THE THYROID AND LACRIMAL GLANDS*
}

BY

\author{
G. SCLARE† AND R. W. LUXTON \\ Crumpsall Hospital, Manchester
}

HASHIMOTо (1912) remarked on the similarity of the form of thyroiditis, described by him and now known by his name, to the lesions of Mikulicz's disease, which include a chronic inflammatory reaction in the lacrimal glands. Only recently, however, has evidence accumulated of a true association between non-infective chronic inflammatory lesions of the thyroid and lacrimal glands (Anderson, Gray, Beck, and Kinnear, 1961 ; Bunim, 1961).

We record here a case in which an inflammatory lesion of the thyroid, considered to bè Riedel's thyroiditis, was followed by fibrous replacement of the thyroid and both lacrimal glands.

\section{Case Report}

An unmarried woman, then aged 52 years, attended the Christie Hospital and Holt Radium Institute in 1948, complaining that both eyes had become prominent during the previous 5 years, the left eye especially so during recent months; she had been aware of a goitre for the past month. On examination, there was bilateral exophthalmos, more marked on the left side, and a diffuse goitre which especially involved the left lobe of the thyroid. The basal metabolic rate was +8 per cent.

1948: The goitre was so hard that malignancy was suspected, but this was not confirmed by biopsy. Histologically, the excised tissue was not recognizable as thyroid, and a diagnosis of "granuloma" was suggested. Review of these slides shows that the parenchyma is totally replaced by proliferating fibroblasts, with abundant inflammatory cells (Fig. 1). Most of these cells are

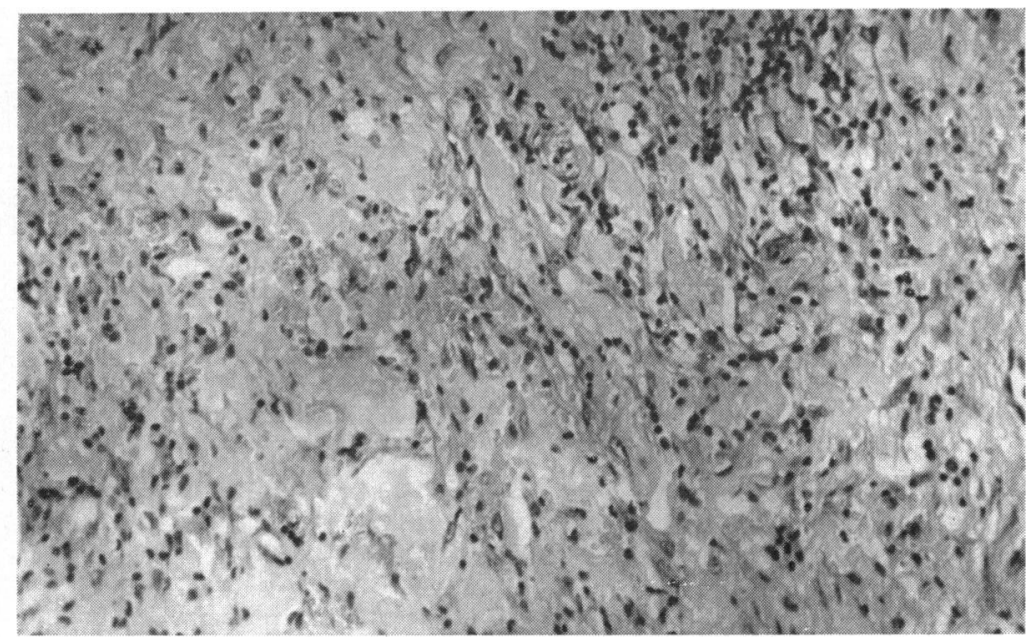

FIG. 1.-Biopsy of thyroid. Fibroblastic proliferation and infiltration by chronic inflammatory cells. No epithelium. Haematoxylin and eosin. $\times 166$.

* Received for publication October 22, 1965.
+ Address for reprints: Bangour General Hospital, West Lothian. 
lymphocytes and plasma cells, while some areas are characterized by large numbers of neutrophils and a few eosinophils. There is no recognizable epithelial component, but as the available tissue measures no more than $1 \mathrm{~cm}$. in diameter it is not possible to say how extensive is the replacement of the thyroid parenchyma. In the absence of extra-thyroidal tissue, the characteristic invasion of muscle cannot be demonstrated, but otherwise the histological picture is that of invasive fibrous thyroiditis, or Riedel's disease.

After biopsy, $x$ ray treatment-3500r in 17 days-was given to the goitre, with no improvement; 8 months later, the goitre was unchanged and the basal metabolic rate was +9 per cent.

1949: When next examined in October, 1949, however, the patient was clinically hypothyroid, with a very hard goitre, nodular and fairly fixed. Exophthalmos was marked, though with little lid retraction; there was some thickening of the eyelids, but no chemosis. $\quad X$ ray of chest and skull at this time revealed no abnormality. The erythrocyte sedimentation rate (Wintrobe) was $36 \mathrm{~mm}$. in $1 \mathrm{hr}$. Serum proteins: albumin $4 \cdot 7$, globulin $3 \cdot 8 \mathrm{~g}$. per cent.

Treatment with dried thyroid, 3 gr. daily, was begun and the hypothyroid symptoms disappeared. A year later, the only complaint was of discomfort in the eyes. The goitre was craggy, and well fixed to the trachea but not to other neighbouring structures.

1952: In January, 1952, after an attack of asthma, the left eye became more prominent and the lids and cheek were swollen, so that the eye was closed for 4 days; the eye was painful and the conjunctiva discharging. In October of that year, clinical examination showed that the eye condition was somewhat improved, there was no change in the goitre, and the patient remained euthyroid on 2 gr. dried thyroid daily. During 1952 also, a barium meal revealed a large gastric ulcer, and a partial gastrectomy was performed.

1955: In April, 1955, the left eye was more painful and the left lacrimal gland was palpable as a hard mass. Exophthalmos was more prominent in the left eye. Orbital "pseudo-tumour" was considered a possible diagnosis, but surgical exploration was not carried out. The goitre seemed smaller than before. A bone survey in the following year showed no significant abnormality. There was not at any stage any evidence of rheumatoid arthritis.

1958: In January, 1958, there was a firm elastic ovoid mass protruding from the left upper orbit, and a hard craggy small goitre. She was still receiving thyroid medication. Serum flocculation tests and protein electrophoresis were normal, and the tanned red cell test for thyroid autoantibody was negative.

1963: The patient complained of breathlessness on exertion, loss of weight, and blood-streaking of the sputum. There was bilateral exophthalmos, very marked on the left; the goitre was unchanged. A diagnosis of bronchial carcinoma was made radiologically; a massive right pleural effusion developed, and the patient died 8 days after admission to Crumpsall Hospital.

Necropsy.-In addition to the thyroid and orbital lesions, which are the subject of this report, the principal finding was a bronchial carcinoma, replacing the greater part of the right lung; the tumour directly infiltrated the pleura, the parietal and visceral pericardium at the base of the heart, and the hilar and tracheo-bronchial lymph nodes. There were no abdominal, cervical, intra-cranial, or skeletal metastases.

There had also been a partial gastrectomy; the remaining part of the stomach showed no abnormality.

Thyroid.-There was a thyroid operation scar. The gland was enclosed by dense adhesions, and could be separated only with great difficulty from the trachea; after dissection so far as was practicable, this tissue, which was nearly all on the left side, weighed $21 \mathrm{~g}$. The gland was very firm; the cut surface was greyish-white, with scattered small foci of calcification and a vertical bar of calcification at the junction of left lobe and isthmus.

Orbits.-There was pronounced protrusion of both eyes, greater on the left than on the right side. The lacrimal glands were markedly enlarged, the left weighing $6 \mathrm{~g}$. and the right $3 \mathrm{~g}$. Each was enclosed by a dense fibrous capsule, and was adherent to the frontal bone. The orbital fat and muscles appeared normal.

There were no significant lesions elsewhere in the body. 


\section{Histology}

Thyroid.-There is no recognizable thyroid tissue, and the gland is totally replaced by hyaline fibrous tissue, in which there are sparse aggregates of lymohocytes and plasma cells (Fig. 2). Foci of calcification are present, especially in the isthmus, and ca'cification is also seen in arterial walls.

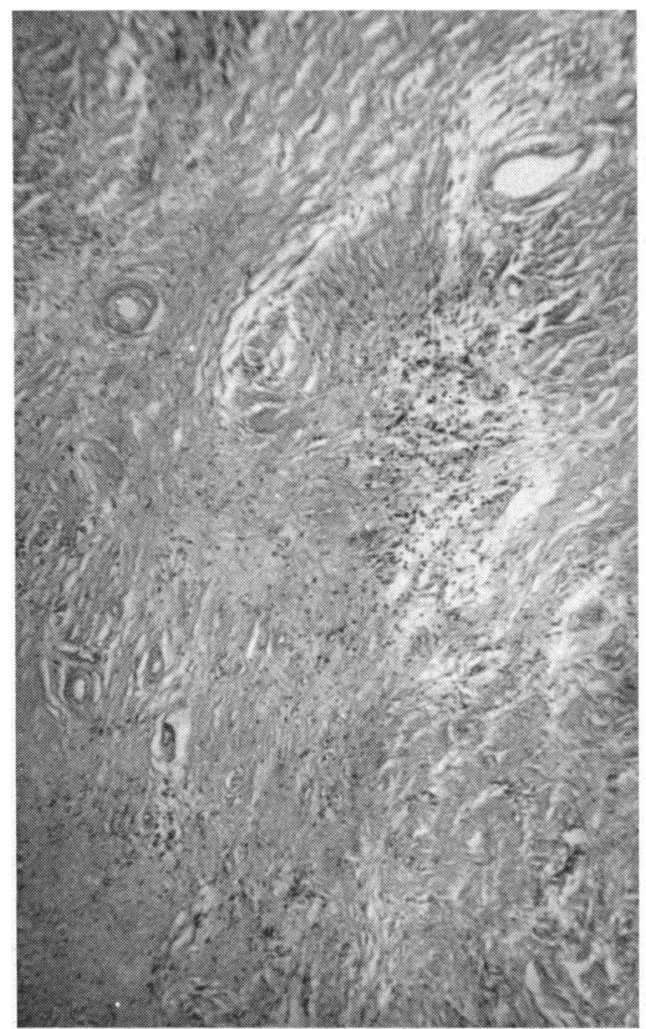

FIG. 2.- Hyaline fibrosis of the thyroid at necropsy 15 years after biopsy shown in Fig. 1. Sparse infiltration by chronic inflammatory cells. Haematoxylin and eosin. $\times 50$.

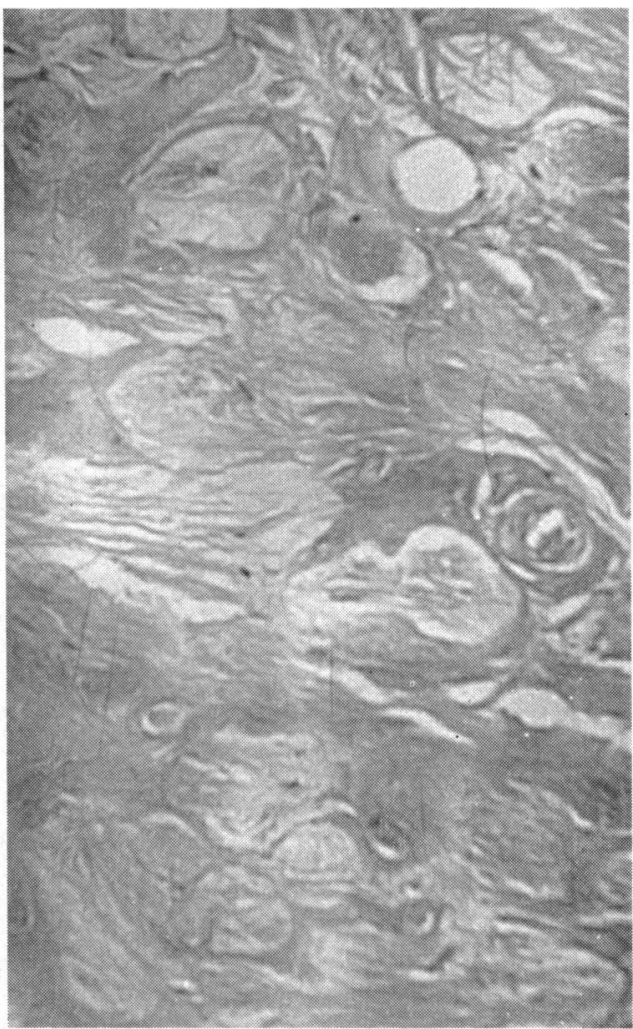

FIG. 3.- Hyaline fibrosis of the lacrimal gland, partly in the form of fibrous rings. Haematoxylin and eosin. $\times 166$.

Lacrimal Glands.-These too are replaced by hyaline fibrous tissue, with sparse chronic inflammatory cells, so that the histological picture closely resembles that of the thyroid; focal calcification is again present, and in the left gland there is also a small focus of ossification. Fat and nerve trunks are incorporated in the fibrous tissue.

Although nothing remains of the acinar or ductal epithelium, the fibrosis in some areas takes the form of fibrous rings rather than bundles, as if outlining the sites of former acini (Fig. 3)

Orbit.-The orbital fat and superior rectus muscle on both sides are free from inflammatory infiltration and fibrosis, and are histologically normal.

Submandibular Salivary Gland.--Sparse infiltration by plasma cells and lymphocytes, abnormal in that in a few instances it involves the parenchyma as well as the peri-ductal tissue.

Larynx.-Infiltration by chronic inflammatory cells, most of them plasma cells, in the submucosa and around the mucous glands. This infiltration is a little in excess of normal.

Pituitary.-A relative increase in eosinophils, and a diminution in basophils. Sparse calcospherites.

The tumour of the $R$. lung is a poorly-differentiated squamous carcinoma.

No significant abnormality is seen in sections of brain, pineal, heart, pancreas, adrenal, and lumbar vertebra. 


\section{Discussion}

Derivation of hyaline fibrosis of the thyroid from an active inflammatory process is clearly shown by comparison of the biopsy and necropsy specimens, and it may be assumed that the similar hyaline fibrosis of the lacrimal glands was similarly derived. The role of irradiation in bringing about the thyroid fibrosis must remain uncertain, but it may have been of little account since equal fibrosis and calcification occurred in the lacrimal gland without the intervention of $x$ ray therapy.

Attention was drawn to the association between thyroid disease and inflammatory lesions of the lacrimal glands by Reese (1935), who described two cases of progressive exophthalmos following thyroidectomy. In both cases the extra-ocular muscles showed the expected chronic inflammatory changes, while identical lesions were found in the lacrimal glands; the intervening orbital tissue was uninvolved, indicating that there had been no spread of inflammation from one tissue to the other. Many years later, Easton and Smith (1961) commented on the histological resemblance between the lesions of non-specific granuloma of the orbit, exophthalmic ophthalmoplegia and Sjögren's syndrome.

Just before the advent of the "auto-immune era" in pathology, Cardell and Gurling (1954) described the histology of the lacrimal glands in three cases of Sjögren's syndrome, and remarked on their resemblance to certain lesions of the thyroid-in the early stage to Hashimoto's disease and in the late stage to myxoedema. With the work of Jones (1958) and Heaton (1958), the area of similarity was extended to include not only age and sex incidence and histological lesions but an increase in serum gamma globulin and abnormal flocculation tests in the serum. Later, it was shown that circulating thyroid autoantibodies were present in a significantly high number of cases of Sjögren's syndrome (Anderson and others, 1961; Bunim, 1961), and that these were not confined to cases with clinical evidence of thyroid disease.

In these circumstances one might expect to find increased numbers of chronic inflammatory cells in the lacrimal glands in cases of clinical thyroiditis and myxoedema, but this is very difficult to demonstrate. One of us (G.S.) has examined the lacrimal glands histologically in twelve cases of myxoedema, in addition to the case reported here, together with over 200 lacrimal glands from other subjects for comparison. It was found that virtually all lacrimal glands in adults show some degree of diffuse plasma cell infiltration and in the majority there are also foci of lymphocytic infiltration. The chronic inflammatory infiltration tends to increase with age, and to be greater in the female than in the male. These findings are in general agreement with those of Waterhouse (1963).

Chronic inflammatory infiltration of the lacrimal glands thus normally reaches its maximum in the group which includes most cases of myxoedema. In only one of the twelve cases of myxoedema was there a very severe inflammatory infiltration of the lacrimal glands; hypothyroidism had supervened after partial thyroidectomy for chronic thyroiditis, and the remaining thyroid tissue showed a much more intense chronic inflammatory infitration than is ordinarily seen in myxoedema. In the other eleven cases, inflammatory infiltration of the lacrimal glands was not certainly beyond normal limits. 
The interest of the present case is that an uncommon lesion of the thyroid-total hyaline fibrosis with focal calcification-is exactly duplicated by an equally uncommon lesion of the lacrimal glands. While partial surgical removal, or irradiation, or both, may have played some part in bringing about fibrosis of the thyroid, no such factors can be implicated in causing fibrosis of the lacrimal glands. It should be noted that protrusion of the eyes was due entirely to enlargement of the lacrimal glands, not to thyrotoxic exophthalmos, and that no inflammation or fibrosis was found in the orbital muscles or fat.

The case of Andersen, Seedorff, and Halberg (1963), in which only biopsy tissue was available for study, is similar in many ways to the present case. The first thyroid biopsy showed severe inflammatory changes, and the description is very suggestive of Riedel's thyroiditis, while the second biopsy 4 years later showed hyaline fibrosis, fewer inflammatory cells and total loss of thyroid parenchyma. In a "pseudo-tumour" of the left orbit, localized to the lacrimal fossa, examined histologically on the occasion of the second thyroid bicpsy, there were chronic inflammatory infiltration, hyaline fibrosis, and focal calcification. The orbital affection was less advanced than in our case, since it was unilateral and islets of wellpreserved lacrimal tissue were identified at the margin of the fibrotic area.

Another case of thyroid and orbital fibrosis, also diagnosed by biopsy, is that of Arnott and Greaves (1965). In this case too the thyroid lesion was thought to be Riedel's thyroiditis. The orbital lesion, which was bilateral, was histologically similar, but may not have involved the lacrimal glands, as it is described as having begun in the lower part of the orbits, later encompassing both eyes. Riedel's thyroiditis has also occurred in association with two other conditions characterized by invasive fibrosis: idiopathic fibrous mediastinitis (Case 19 of Haché, Woolner, and Bernatz, 1962) and retroperitoneal fibrosis (Thomson, 1963). These examples of orbital, mediastinal, and retroperitoneal fibrosis are alike in involving spacefilling fibro-fatty tissue, and differ from the present case in which a specific exocrine gland is involved.

\section{Summary}

Total fibrosis of the thyroid and both lacrimal glands occurred in a 67-year-old woman, following Riedel's thyroiditis. This case strengthens the growing evidence for an association between chronic inflammatory lesions of the thyroid and lacrimal glands.

\section{REFERENCES}

Andersen, S. R., Seedorff, H. H., and Halberg, P. (1963). Acta ophthal. (Kbh.), 41, 120.

ANDERSON, J. R., Gray, K. G., BeCK, J. S., and Kinnear, W. F. (1961). Lancet, 2, 456.

Arnott, E. J., and Greaves, D. P. (1965). Brit. J. Ophthal., 49, 1.

Bunim, J. J. (1961). Ann. rheum. Dis., $20,1$.

Cardell, B. S., and Gurling, K. J. (1954). J. Path. Bact., 68, 137.

EAston, J. A., and Smith, W. T. (1961). Ibid., 82, 345.

Haché, L., Woolner, L. B., and Bernatz, P. E. (1962). Dis. Chest, 41, 9.

HASHIмOTO, Н. (1912). Arch. klin. Chir. (Berl.), 97, 219.

HEATON, J. M. (1959). Brit. med. J., 1, 466.

JONES, B. R. (1958). Lancet, 2, 773.

ReESE, A. B. (1935). Arch. Ophthal. (Chicago), 13, 855.

Thomson, A. D. (1963). Brit. med. J., 2, 311.

WATERHOUSE, J. P. (1963). Proc. roy. Soc. Med., 56, 911. 